\title{
VERSITA
}

\section{The Committee of the Regions: \\ A Springboard for the Citizens}

\author{
Javier Mendoza Jiménez \\ University of Latvia \\ Raina Bulvaris 19, \\ Riga LV-1050, Latvia \\ E-mail: mendozajimenez.javier@gmail.com
}

\begin{abstract}
This study focuses on the relation between the Committee of the Regions (CoR), an advisory institution of the European Union defined as the political assembly of holders of a regional or local electoral mandate serving the cause of European integration, and the democratic deficit, understood as the effective ways of citizens' participation in the institutional decision making. The work hypothesis is that the CoR, in spite of being mostly unknown to citizens, could be an effective tool for tackling the democratic deficit. Through qualitative interviews and surveys at different levels, the article analyzes the current situation and the potential opportunities of the CoR in its relation with citizens.
\end{abstract}

Keywords: citizens' participation, the Committee of the Regions, democratic deficit, European Citizens Initiative

\section{Introduction and literature review: "it's the democracy, stupid!"}

Direct democracy is 'the eternal Cinderella of European public law' (Eijsbouts \& Claes, 2007, pp. 353-356) and it has been one of the major claims of the several social movements that countries like Spain (15M), Greece, Italy and even the USA have seen. Resolute protest movements like Occupy Wall Street are a clear indicative that civil society asks for a role bigger than simply spectators in the urgent and needed discussion on the political direction that Europe ought to go. Meanwhile, loss of trust in politicians is increasing day by day. The institutions and political bodies give the impression of living in an emergency state where only the economic aspects of the crisis matter. On the other hand, the population seems to be shouting "It's the democracy, stupid!" to paraphrase Bill Clinton's slogan during in the 1996 US elections. 
Only one of the EU institutions the European Parliament (hereinafter EP) is directly elected by the citizens and its powers, although increased through the years and the adoption of the successive Treaties, are still far from being a complete tool for the accounting of the EU's actions. At that point, European elections are even defined as "second order elections" (Crum \& Fossum, 2009, pp. 249-271; Franklin \& Hobolt, 2011, pp. 67-76).

A major concept associated with this lack of legitimacy that has caught wide attention in the literature is the democratic deficit. This concept appears to have different meanings for different people (Crombez, 2003, pp. 101-120). Goodhart (2007, pp. 567-584) states that four broad types of democratic deficit emerge from the vast and diverse literature on this subject: institutional, performance, secondary, and structural deficits. Gabel (2002, pp. 665-674) conceives it as the distance between policy makers and citizens resulting from the transfer of political authority from the national to the EU level and in the same line Franklin and Hobolt (2011, pp. 67-76) define it as the gap between the powers transferred to the Community level and the control of the elected (European) Parliament over them.

On the origins and key points, Majone denied the existence of the democratic deficit and attributes it to the voters preferences for national sovereignty and concludes that "these being the preference of the voters $[\ldots]$ the European's democratic deficit is democratically justified" (Majone, 2002, pp. 5-28). Majone also draws attention to the problems of legitimacy of the non-majoritarian institutions and its relevance for the EC (today's EU). Føllesdal \& Hix (2006, pp. 533-562) replied to those arguments by saying that a democratic policy requires contestation for political leadership and over policy. This aspect is an essential element of even the 'thinnest' theories of democracy, yet it is conspicuously absent in the EU.

The first need for the study is, therefore, having a definition of what is democratic deficit. We conceptualized it as the effective ways of citizens' participation in the institutional decision making. In other words, the gap between citizens and institutions in terms of participation in the decision-making process. One of the main problems of the democratic deficit is the high influence of the subjective perception and of the opinion and feelings of the citizens regarding their representation in the institutions.

Hupe and Edwards (2011, pp. 1-18) explore the problem of political accountability and related to that, a recent survey carried out by Burson-Marsteller (2011, pp. 1-42) shows an alarming decrease in the citizens' trust towards the European Parliament and the European Commission by a third and the situation is even 
worse in the case of local and central government, where more than one half of the respondents have lost trust in their own institutions.

Thus, a decision was made to take an innovative approach to face the democratic deficit and focus the attention on one of the advisory bodies of the European Union that is closest to the citizens - the Committee of the Regions (hereinafter $\mathrm{CoR}$ ) which represents the EU regions. The author's hypothesis is that the CoR is an unknown institution (by the citizens) that could constitute an effective tool to improve the ways of involvement of society in the EU's decision-making process.

The CoR, representing the post-Maastricht institutionalization of sub-national actors in the EU policy process, can be conceptualized as an advisory body possessing both reactive and proactive modes of operation (Farrows \& McCarthy, 1997, pp. 23-49). Starting from the Maastricht Treaty, there has been a trend toward redistribution of state functions away from the classical nation-state: upward towards supranational institutions, and downward towards local and regional bodies (Roht-Arriaza, 1996, p. 413).

The role of the CoR in literature has been normally linked to the concept of multi-level governance by several scholars such as Börzel and Heard-Lauréote (2009, pp. 135-151), Clark and Rohrschneider (2009, pp. 645-664), Crum and Fossum (2009, pp. 249-271), and Scharpf (2009, pp. 173-204). In this field the CoR has already stated its intention to draw up the European Union Charter on multi-level governance (CIVEX V Document 34) and in other documents it has highlighted that regional authorities are often largely responsible for the implementation of policies related to employment, education and training (ECOS V Document 33).

Regarding its influence, Nash (1994, pp. 289-294) considered that once the CoR was established, launched and baptized the development of its potential will be watched and monitored with great interest. Farrows and McCarthy (1997, pp. 23-49) are two of the few scholars who devoted a study on the impact that the CoR could have on EU legislation. Possibly one of the most explored ways in the scarce amount (compared with other EU institutions, especially those belonging to the "golden triangle") of existing literature on the CoR would be its relation with the third level governance (Christiansen, 1996, pp. 93-116; Hooghe \& Marks, 1996, pp. 73-92; McCarthy, 1997, pp. 439-454). This means that, additionally to the European and national level where the legislation is proposed and discussed, there is the regional level where the legislation is implemented. 
A major part of the literature linked with the CoR was developed within five years after its establishment in 1994 and a few articles can be found after that. This shows the low relevance of this institution in the EU context in terms of theoretical development and it reflects that, as a result of its formal weakness, the Committee of the Regions is often presumed to be inconsequential in the development of European Union policy (Warleigh, 1997, pp. 101-107).

A study conducted by Hönnige and Panke (2012, pp. 1-22) concerning the role of this institution in the EU (together with the European Economic and Social Committee, EESC) measures through the distribution of subjects among MEP and Permanent Representatives the influence (defined as the ability of a committee to shape the content of a position or a policy outcome in line with its own opinions) of both CoR and EESC in the policy-making of the European Union and concludes that the factors that provide for bigger influence are the "speed with which they produce recommendations, the quality of the recommendations and the resonance with the addressees' prior beliefs" (Hönnige \& Panke, 2012, pp. 1-22).

Below, the current paper will briefly explain the methodology used for obtaining the results given in the third part and finally the conclusions and further outlines of investigation.

\section{Research method}

The main tool for the methodology of the study, apart from the revision of the CoR documents, was a questionnaire sent to a sample of 280 members and alternates of the Committee of the Regions who were asked to give their opinion on different topics. The questions from the original survey were divided in three groups: the first concerns the role of the CoR in tackling the democratic deficit as well its influence on the EU decision making, the second is addressed to the relation among the CoR and the European Parliament while the third regards the $\mathrm{CoR}$ and the citizens. The survey was translated into five languages: English, Spanish, French, German and Italian, in order to make it more accessible to the respondents, and it was sent electronically to them. 


\section{Results of the survey}

The survey produced 13 complete answers distributed as shown in Table 1. The analysis of the answers is divided into the three different sections mentioned above.

\section{Table 1. Characteristics of respondents}

\begin{tabular}{|l|l|}
\hline Category & Results \\
\hline Number of respondents & 13 out of 334 members of the CoR \\
\hline Gender & 13 men and 0 women \\
\hline Position within the CoR & 10 members and 3 alternate members \\
\hline Countries & $\begin{array}{l}\text { Germany (3); Spain (2); France (2); Italy (2); Czech } \\
\text { Republic (1); Austria (1); Finland (1); Denmark (1); } \\
\text { Poland (1) }\end{array}$ \\
\hline $\begin{array}{l}\text { Political affiliation } \\
\text { (respondents can } \\
\text { belong to more than } \\
\text { one) }\end{array}$ & $\begin{array}{l}\text { Party of European Socialists (7), European People's } \\
\text { Party (6) }\end{array}$ \\
\hline $\begin{array}{l}\text { V-Commission for Territorial Cohesion Policy / } \\
\text { V-Commission for Natural Resources / NAT (4) } \\
\text { V-Commission for Economic and Social Policy / } \\
\text { ECOS (2) } \\
\text { V-Commission for Education, Youth, Culture and } \\
\text { Research / EDUC (2) } \\
\text { V-Commission for Environment, Climate Change and } \\
\text { Energy / ENVE (1) }\end{array}$ \\
\hline $\begin{array}{l}\text { Number of respondents } \\
\text { that would like to } \\
\text { of the study }\end{array}$ & \begin{tabular}{l}
10 out of 13 \\
\hline
\end{tabular} \\
\hline
\end{tabular}

Source: Author's elaboration 


\subsection{The role of CoR in the EU framework}

\subsubsection{Contribution of the CoR to reduce the democratic deficit}

The CoR is mainly seen by the members as a useful and active agent in tackling the democratic deficit. Improvement of EU communication issues on the regional and local level is in line with the communication strategy of the CoR of "going local" in one remarked aspect. According to the respondents, "the CoR helps to make Europe more present in the regions" and it "calls for the bottom-up approach in the EU decision-making procedure by initiating active participation in the inter-institutional legislative dialogue". The creation of synergies and the introduction of the regional view within the EU framework are also emphasized by different members. The principle of subsidiarity is one of the main issues that the respondents consider positive. The CoR is defined as the "guardian" of one of the general principles of the EU law. The relation with other EU institutions, especially with the EP is another contribution of the CoR, in presenting opinions and proposals to them. Finally, the direct election of the members of the CoR by the citizens at regional and local level (for regional and local level, not for the $\mathrm{CoR}$ itself) is also seen as one of the contributions for reducing the democratic deficit.

There are also less optimistic opinions regarding the effective contribution of the institution and an answer that deserves particular attention since the respondent reduces the magnitude of the democratic deficit by expressing that "the members of the Council and the European Parliament are directly elected by citizens".

\subsubsection{Contribution of the CoR to EU decision-making}

Five members agree that the CoR should be consulted in more topics, thus giving it better chance to express its opinions. A larger number of meetings and the better quality of the reports are also mentioned by several respondents as well as a better collaboration with the EP due to the mutual presence of members when discussing similar topics. One of the respondents was clear on the impossibility of increasing the influence of the CoR since the power struggle between "the Council, the Commission and the Parliament overshadow any real influence". However, no comments have been made on the direction of increasing influence through a better recognition of the citizens which confirms that this is already a path quite unexplored by the members. It seems then that the path for a stronger influence of the CoR has been more focused on the work inside the EU institutions framework, while the possibility of a bottom-up approach with a major support of the citizens and the civil society has not been estimated yet. 


\subsection{The CoR and the European Parliament}

\subsubsection{Collaboration among the $\mathrm{CoR}$ and the European Parliament}

A disparity of opinions characterizes the answers obtained to these questions. On the "bright side of life", quoting Monty Python, six members have defined the collaboration of the CoR and the EP as positive and increasing with the years, and one of the respondents even expressed his 85 per cent satisfaction level. Meanwhile, one given answer labeled it as, "good but not enough", emphasizing the obstacle of the merely advisory role of the CoR as an impediment to a stronger relation. Another respondent exposed that it is mostly limited to the exchange of rapporteurs in similar commissions although he agreed that there is a growing tendency. In a similar manner, yet another respondent highlighted the existence of previous tensions from the part of both institutions and claims for a regular work of exchange among the institutions.

Finally, in a more "pessimistic" (or realistic) vision, two respondents qualified the relation as "not much of a collaboration" and "a very polite attitude from the Parliament, but no real influence". Finally, the fact that the CoR has replicated the political structure of the EP has led to problems according to one respondent's opinion.

\subsubsection{Improvement of relation with the EP}

On this question, most proposals by the members focus on the invitation of the EP members to the commissions of the CoR and also on increasing the cases in which CoR is consulted with and personal meetings. A more introspective reflection, invites the institution to think about its inner values especially its role in keeping the sub-national levels and the diversity. On the other hand, some voices asked directly for the establishing of the collaboration and considered improving the current relation impossible.

\subsection{Relevance of the CoR for the citizens}

\subsubsection{Relation between CoR and European Citizens Initiative}

This topic has been one of the most discussed ones of all the answers of the survey. The arguments in favour of an active role of the CoR promoting the European Citizens Initiative (ECI) are that the CoR could act as a means for spreading information on each territory especially through the local media. The role of the CoR outside the EU territory is also stressed when addressing the influence of "the democratic approach, especially concerning ethnic disparities" 
in the Balkans. This could open a way to profit the potential for visibility outside the EU.

Other respondents opposed to extending relation between the CoR and the ECI arguing that the role of the CoR does not fall into this field and that the enabled mechanism is enough to guarantee the correct development of the CoR. To be more specific, this opposition is expressed by two respondents who considered that the CoR is an advisory body of the Council, the EP and the Commission and it is among its functions to ensure the reduction of the democratic deficit but not to be a mouthpiece for individual initiatives since there is a concrete procedure for these kind of initiatives allowing the participation of civil society.

Finally, some members also expressed their doubts, which would require a more detailed approach. One respondent proposed several conditions for a better involvement such as a link to every regional page with the CoR and a more efficient spreading of the information about who has which seat and what he/she is doing in the CoR and the potential benefits for regional interests.

\subsubsection{Awareness of citizens about member's participation in the CoR and the activities of the institution}

Most respondents perceive that citizens have little awareness about the CoR, which is confirmed by information included for example in the Eurobarometer Report No 307. Some members related a good recognition with communication through the local media and the knowledge of personal information about local authorities while others complained about the little attention given to the CoR in the local press. Even so, the institution's efforts in improving this aspect were recognized, especially through invitation to local journalists. In general, the respondents considered that the lack of interest in information about the EU has had a negative influence on the recognition of the CoR and also pointed out the lack of education programs regarding the EU issues.

\subsubsection{Programs to increase CoR's visibility in 2014 EP elections}

A few actions are already planned relating to the EP elections. Some members are planning to spread information about the rights and opportunities of "European citizens" in order to encourage voting in the 2014 European Parliament elections and even a project entitled "Europe Week - project at schools" is being devised. This situation contrasts with the general aspiration of the CoR to "contribute to helping the EU regain citizens' trust [...] in the run up to the 2014 elections" and seems to make a breach in the general strategy of the CoR and the specific case of its members, which could result in a loss of credibility in the eyes of the society. 


\section{Conclusions: a springboard for citizens but is there water in the pool?}

The CoR is an active institution in many ways and directly or indirectly influences many European policies, especially in those fields that closely affect its members such as the regional and the cohesion policy. Despite amounting just to one per cent of the EU administration costs, the CoR participates in many spheres of public life, even in those in which the Treaty of Lisbon does not obligate the Commission, the European Parliament and/or the Council to consult it. As a result, this advisory body produces a noticeable amount of information and possesses both: a recognized expertise in some specific topics and a multitude of links with other EU institutions.

The different responses give some idea about the diverse positions of the members regarding the CoR activities and potential. Some common aspects can be extracted, such as the recognition of the work that the CoR is carrying out on the utility of exchanges with other EU institutions, the members' increase in knowledge about EU issues and also the improvement of European programmes' management. No clear agreement can be found in the effective role that the CoR should have in promoting the citizens' participation, especially regarding the ECI. Although the possibilities for that are recognized, not many actions have been put in place and the potential in this field is still underestimated.

The CoR can be defined as one of the big unknown bodies of the European Union both for citizens and for academics. In order to increase its visibility the committee should focus on the sphere of citizens' participation, a field in which the institution is still not very active but which holds numerous opportunities to increase its relevance for the citizens.

Metaphorically speaking, the CoR could be considered the EU's "customs officer". It has access to all the products that are in transit from the European Union to the citizens but also has to be able to facilitate the communication and understanding between both parts. Due to its unique position this advisory body of the EU enjoys a democratic legitimacy from the citizens which elect its members as local representatives and from the Member States and Council which validate those constituents.

The issue of multi-level governance could provide, not only for the CoR but especially for the citizens, the opportunity to increase their participation and their influence. It could be an effective instrument to overcome the general impression that the role of EU citizens is limited to the reactive position of 
voting every five years. However, a tool-box is useless without a good carpenter or at least without someone interested in using it correctly. The projects outside the EU in which the CoR is involved (for example ARLEM and CORLEAP) provide a good "user manual" for the multi-level governance. The experience gained there could be the basis on which the CoR, and especially its members, could support their arguments in favour of shaping the EU policies. This is, in the author's opinion, the path that the institution should follow to achieve better results also inside the EU.

A mere budget increase would not solve the problems, it is also necessary to foster the CoR's members' implication. In the EU structure, the CoR has a privileged advantage in the direct contact between its members and the citizens that is not enjoyed by the European Parliament, the Commission or the Council due to the physical placement of its members in Brussels or in the countries' capitals. With adequate communication channels and higher relevance of the EU issues on the regional representative agenda, synergies could be created and the citizens' interest could be increased not only on the issues themselves but also on the possible ways for gaining influence on them. This would diminish the discouragement and the impotent feeling within the present situation which has generated a sense of mistrust toward the elected representatives at every level.

The CoR could have a bigger impact on tackling the democratic deficit. It could be the springboard, the platform that would permit the citizens to have the necessary impulse to jump from the regional and local framework to the European one. It is represented in projects both outside and inside the EU and its members have a high level of expertise in the management of European programmes that could constitute a valuable asset for a better management which is especially relevant in the current panorama. Quoting the President of Uruguay, José Mujica, "the crisis is not economical but political" and the components of the CoR, which are directly related with citizens burdened by the crisis, could play a bigger role in tackling an important issue inside the democratic deficit as it is the vertical accountability from the citizens that would manage more understandable information.

To achieve its aims, the CoR would need not only to repair the bridges already built for its communication with the society, profiting from the existing tools like the "Europe in Your Region" project, but it should seek to construct new ones, pushing for innovative ways of participation that would transform its representatives from spectators of the EU politics into active actors putting doses of reality inside the Brussels bubble. In many communication materials the role of the regions in the $\mathrm{EU}$ in terms of implementing legislation, creating jobs and similar is highlighted, 
but a blurry panorama can be observed regarding the regional influence on the legislation, the regulation of the jobs or the sharing of the CAP for putting some examples. The CoR should focus its efforts on the relevance not only of its political influence but also in spreading regional sensitiveness. The way that has been explored in this study is the CoR's potential role in tackling the democratic deficit and the increase of citizens' involvement in the EU decision making process. Initiatives like the ECI are still in embryonic stage with an uncertain future. The regional and local authorities, and hence the CoR, alone are not going to solve the problem of the democratic deficit, there is not a magic stick for that. However, the CoR could help to reinforce ways of communication, create new ones and ensure that the voice of the citizens is heard at the European level.

Javier Mendoza Jiménez is Associate Researcher at the University of Latvia. He has recently completed the master's degree in European studies there and for the last two years has been awarded with a scholarship at the University of La Laguna (Spain). His fields of research include international students, tourism, alternative education systems (with several articles published in the field) and, more recently, European studies.

\section{References}

Börzel, T. A. \& Heard-Lauréote, K. (2009), 'Networks in EU multi-level governance: concepts and contributions,' Journal of Public Policy, vol. 29, no. 2, pp. 135-151. http://dx.doi.org/10.1017/S0143814X09001044

Burson Marsteller (2011), Trust and Purpose Survey 2011, Brussels: Burson-Marsteller EMEA, pp. 1-42.

Christiansen, T. (1996), "Second thoughts on Europe's 'third level': the European Union's Committee of the Regions," Publius: The Journal of Federalism, vol. 26, no. 1, pp. 93-116. http://dx.doi.org/10.1093/oxfordjournals.pubjof.a029842

Clark, N. \& Rohrschneider, R. (2009), 'Second-Order Elections versus First-Order Thinking: How Voters Perceive the Representation Process in a Multi-Layered System of Governance,' European Integration, vol. 31, no. 5, pp. 645-664. http://dx.doi.org/10.1080/07036330903145906

Crombez, C. (2003), 'The Democratic Deficit in the European Union: Much Ado about Nothing?' European Union Politics, vol. 4, no. 1, pp. 101-120. http://dx.doi.org/10.1177/1465116503004001583

Crum, B. \& Fossum, J. E. (2009), 'The Multilevel Parliamentary Field: a framework for theorizing representative democracy in the EU,' European Political Science Review, vol. 1, no. 2, pp. 249-271. http://dx.doi.org/10.1017/S1755773909000186 
Eijsbouts, W. \& Claes, M. (2007), 'Democracy and the Union: Dressing up Cinderella,' European Constitutional Law Review, vol. 3, pp. 353-356.

Farrows, M. \& McCarthy, R. (1997), 'Opinion Formulation and Impact in the Committee of the Regions,' Regional \& Federal Studies, vol. 7, no. 1, pp. 23-49. http://dx.doi.org/10.1080/13597569708420994

Føllesdal, A. \& Hix, S. (2006), 'Why there is a Democratic Deficit in the EU: A Response to Majone and Moravcsik,' JCMS: Journal of Common Market Studies, vol. 44, no. 3, pp. 533-562.

http://dx.doi.org/10.1111/j.1468-5965.2006.00650.x

Goodhart, M. (2007), "Europe's democratic deficits through the looking glass: the European Union as a challenge for democracy," Perspectives on Politics, vol. 5, no. 3, pp. 567-584.

http://dx.doi.org/10.1017/S1537592707071551

Hönnige, C. \& Panke, D. (2012), 'The Committee of the Regions and the European Economic and Social Committee: How Influential are Consultative Committees in the European Union?' JCMS: Journal of Common Market Studies, vol. 51, no. 3, pp. 452-471. http://dx.doi.org/10.1111/j.1468-5965.2012.02313.x

Hooghe, L. \& Marks, G. (1996), “'Europe with the regions': channels of regional representation in the European Union," Publius: The Journal of Federalism, vol. 26, no. 1, pp. 73-92. http://dx.doi.org/10.1093/oxfordjournals.pubjof.a029841

Hupe, P. \& Edwards, A. (2011), 'The accountability of power: Democracy and governance in modern times,' European Political Science Review, vol. 1, no. 1, pp. $1-18$.

Majone, G. (2002), "Europe's 'democratic deficit': The question of standards," European Law Journal, vol. 4, no. 1, pp. 5-28. http://dx.doi.org/10.1111/14680386.00040

McCarthy, R. E. (1997), “The Committee of the Regions: an advisory body's tortuous path to influence," Journal of European Public Policy, vol. 4, no. 3, pp. 439-454. http://dx.doi.org/10.1080/13501769780000091

Nash, M. (1994), 'The committee of the regions: A committee for Europe,' Contemporary Review, vol. 265, no. 1547, pp. 289-294.

Roht-Arriaza, N. (1996), 'Committee on the Regions and the Role of Regional Governments in the European Union,' Hastings Int'l \& Comp. L. Rev., vol. 20, p. 413.

Scharpf, F. W. (2009), 'Legitimacy in the multilevel European polity,' European Political Science Review, vol. 1, no. 2, pp. 173-204. http://dx.doi.org/10.1017/ S1755773909000204

Warleigh, A. (1997), 'A committee of no importance? Assessing the relevance of the Committee of the Regions,' Politics, vol. 17, no. 2, pp. 101-107.

http://dx.doi.org/10.1111/1467-9256.00040 